\title{
KORELASI ANTARA KARAKTER BUAH TERUNG (Solanum melongena L.) DAN PENGUJIAN VIABILITAS BENIH SETELAH DISIMPAN 6 BULAN
}

\author{
Dwina Safareta Elba, Nyimas Sa'diyah \& Yayuk Nurmiaty \\ Jurusan Agroteknologi, Fakultas Pertanian, Universitas Lampung \\ Jln. Prof. Soemantri Brodjonegoro, No. 1, Bandar Lampung 35145 \\ E-mail: safaretaelba@yahoo.com
}

\begin{abstract}
ABSTRAK
Tujuan penelitian ini adalah untuk mengetahui hubungan antara karakter buah dan hasil, serta untuk mengetahui pengaruh bentuk buah terhadap viabilitas benih terung yang telah disimpan 6 bulan. Penelitian ini dilaksanakan di Kebun Percobaan BPTP Natar dan Laboratorium benih Universitas Lampung dari bulan November 2013 sampai Mei 2014. Pengujian seleksi karakter buah terung dilaksanakan dengan percobaan tanpa ulangan dan menggunakan analisis Korelasi Pearson dan Sperman. Korelasi Pearson digunakan untuk menyatakan besar hubungan linear antara dua variabel untuk data kuantitatif. Korelasi Sperman digunakan untuk mengetahui korelasi dua variabel data kualitatif dengan menggunakan skor atau rangking. Pengujian viabilitas benih menggunakan rancangan percobaan teracak sempurna dan analisis Korelasi Sperman. Hasil uji korelasi menunjukkan bahwa bobot buah per tanaman berkorelasi positif dengan diameter buah, panjang buah per tanaman, bobot benih per tanaman, dan bentuk buah. Pengujian viabilitas benih menunjukkan tidak adanya korelasi antara perlakuan bentuk buah terung ungu dan viabilitas benih. Dari hasil pengujian viabilitas benih terung ungu bahwa perlakuan bentuk buah tidak berpengaruh terhadap viabilitas benih yang dihasilkan kecuali pada pengujian bobot kering kecambah normal. Bobot kering kecambah normal paling tinggi berasal dari bentuk buah skor 3 yaitu bentuk buah bulat sedikit oval.
\end{abstract}

Kata kunci : Korelasi, terung ungu, viabilitas benih.

\section{PENDAHULUAN}

Menurut Badan Pusat Statistik (2013), produktivitas tanaman terung di Indonesia pada tahun 2012 yaitu 518.827 ton/ha mengalami kenaikan sejak tahun 1997 sampai tahun 2012 sebesar 1,43\%. Meskipun produksi terung nasional tiap tahun cenderng meningkat namun produksi terung di Indonesia masih rendah dan hanya menyumbang $1 \%$ dari kebutuhan dunia (Simatupang, 2010). Hal ini antara lain disebabkan karena luas lahan budidaya terung yang masih sedikit dan bentuk kultur budidayanya masih bersifat sampingan dan belum intensif.

Salah satu upaya agar produksi terung lebih intensif maka dapat ditempuh dengan menggunakan varietas unggul. Untuk memperoleh varietas unggul dapat dilakukan melalui pemuliaan tanaman sehingga memperoleh daya hasil yang lebih tinggi. Untuk memperoleh informasi tentang berbagai genotipe terung perlu dilakukan seleksi terhadap genotipe-genotipe yang akan digunakan pada proses pemuliaan selanjutnya untuk mencapai varietas unggul baru (Simanjuntak, 2003).

Salah satu faktor yang mempengaruhi seleksi adalah korelasi antara hasil dan komponen hasil.
Korelasi antarkarakter untuk mengetahui keeratan hubungan antarkarakter. Pengetahuan tentang adanya korelasi antar sifat-sifat tanaman merupakan hal yang sangat berharga dan dapat digunakan sebagai dasar program seleksi agar lebih efisien karena seleksi bisa dilakukan lebih awal (Chozin et al., 1993 yang dikutip oleh Ganefianti et al., 2006). Selain itu korelasi antarkarakter digunakan untuk seleksi tidak langsung, sehingga seleksi yang digunakan lebih mudah (Sudarmo, 2007) dan seleksi tidak langsung juga dapat menghemat biaya dan tenaga.

Penyimpanan benih merupakan salah satu penanganan pascapanen terung yang penting dari keseluruhan teknologi benih dalam memelihara kualitas atau mutu. Kemunduran benih merupakan proses penurunan mutu secara berangsur-angsur dan kumulatif serta tidak dapat balik (irreversible) akibat perubahan fisiologis yang disebabkan oleh faktor dalam (Astuti, 2004)).

Tujuan dari penelitian ini adalah untuk mengetahui hubungan antara karakter buah dan hasil, serta untuk mengetahui pengaruh bentuk buah pada viabilitas benih terung ungu yang telah disimpan 6 bulan. 


\section{BAHAN DAN METODE}

Penelitian ini dilaksanakan dari November 2013 sampai dengan Mei 2014. Kegiatan uji korelasi terung dilaksanakan di Kebun Percobaan Balai Pengkajian dan Penerapan Teknologi, Desa Negara Ratu, Kecamatan Natar, Kabupaten Lampung Selatan. Pengujian viabilitas benih dilaksanakan pada bulan April 2014, bertempat di Laboratorium Benih Universitas Lampung.

Pengujian seleksi karakter buah terung dilaksanakan dengan percobaan tanpa ulangan dan menggunakan analisis Korelasi Pearson dan Korelasi Sperman. Korelasi Pearson digunakan untuk menyatakan besar hubungan linear antara dua variabel untuk data kuantitatif dan kedua variabel adalah bivariat yang berdistribusi normal. Pengujian Korelasi Sperman digunakan untuk mengetahui korelasi dua variabel data kualitatif dan tidak terdistribusi normal dengan menggunakan skor atau rangking (Nugroho dkk., 2008). Pengujian viabilitas benih dengan rancangan percobaan teracak sempurna dan analisis Korelasi Sperman. Bahan yang digunakan untuk percobaan korelasi antara karakter buah terung dan hasil adalah benih lokal dari perusahaan PT. Andal Hasa Prima.

Percobaan seleksi genotipe tanaman terung ungu dimulai dengan persemaian benih dalam rumah kaca dengan media campuran tanah dan pasir dengan perbandingan $1: 1$. Persemaian dilakukan selama satu bulan setelah itu pindah tanaman pada petakan berukuran $18 \mathrm{~m}$ x $20 \mathrm{~m}$ dan jarak tanam $70 \mathrm{~cm} \times 60 \mathrm{~cm}$. Benih terung di tanaman sebanyak 522 genotipe. Petak tersebut terdapat 18 baris tanaman, setiap baris terdapat 29 lubang tanam. Karakter agronomi yang diamati adalah buah terung umur 11 minggu setelah tanam pada fase generatif.

Pengujian viabilitas benih menggunakan metode uji diatas kertas. Bahan yang digunakan untuk percobaan viabilitas benih adalah benih hasil seleksi genotipe terung ungu. Pengujian dilakukan menggunakan 4 perlakuan dan 8 ulangan. Perlakuan yang digunakan adalah bentuk buah yang dibedakan menjadi 4 kriteria bentuk dengan nilai skor yang berbeda yaitu bentuk buah bulat skor, bentuk buah bulat sedikit oval skor 3, bentuk buah oval skor 5, dan bentuk buah lonjong skor 7 (IBPGR, 1990).

Peubah yang diamati pada percobaan korelasi antara karakter buah terung dan hasil yaitu bentuk buah, diameter buah, bobot buah, bobot benih per buah, warna batang dan warna buah. Peubah yang diamati pada pengujian viabilitas benih setelah disimpan 6 bulan yaitu bobot 100 butir, total kecambah normal, keserempakan kecambah benih, kecepatan berkecambah, dan berat kering kecambah normal.

\section{HASIL DAN PEMBAHASAN}

Berdasarkan uji korelasi yang telah dilakukan, terlihat bahwa terdapat keeratan hubungan antara karakter yang satu dengan karakter yang lainnya. Hasil uji korelasi semua komponen hasil pada tanaman terung disajikan pada Tabel 1 dan 2. komponen hasil bobot buah per tanaman memiliki korelasi yang positif dengan diameter buah dan panjang buah. Hal ini menunjukkan bahwa semakin berat bobot buah yang dihasilkan maka akan semakin lebar diameter buah, serta akan diikuti dengan semakin panjang buah terung. Komponen bobot buah per tanaman berkorelasi positif dengan bobot benih per tanaman, yang artinya semakin berat suatu bobot buah per tanaman maka akan semakin banyak bobot benih yang dihasilkan.

Komponen diameter buah berkorelasi positif dengan panjang buah per tanaman dan bobot benih per tanaman. Hal ini menunjukkan bahwa semakin lebar diameter buah per tanaman maka akan diikuti dengan semakin panjang buah dan semakin berat bobot benih per tanaman. Komponen panjang buah per tanaman berkorelasi positif dengan bobot buah per tanaman dan diameter buah per tanaman. Hal ini menunjukkan semakin panjang buah maka akan diikuti dengan semakin berat bobot buah dan semakin lebar diameter buah per tanaman. Panjang buah berkorelasi positif dengan bobot benih per tanaman, yang berarti semakin panjang buah maka akan semakin banyak bobot benih yang dihasilkan.

Tabel 1. Koefisien korelasi antara komponen buah dan hasil pada terung ungu

\begin{tabular}{lcccc}
\hline Variabel Hasil & Bobot Buah & Diameter Buah & Panjang Buah & Bobot Benih \\
\hline Bobot Buah & 1 & & & \\
Diameter Buah & $0,92^{*}$ & 1 & & \\
Panjang Buah & $0,68^{*}$ & $0,50^{*}$ & 1 & \\
Bobot Benih & $0,58^{*}$ & $0,47^{*}$ & $0,45^{*}$ & 1 \\
\hline
\end{tabular}

Keterangan : * berkorelasi pada taraf 0,05 , menggunakan analisis Korelasi Pearson 
Koefisien korelasi antara bentuk buah per tanaman dengan diameter buah per tanaman menunjukkan berkorelasi positif, hal ini menunjukkan bahwa semakin besar skor bentuk buah per tanaman maka akan semakin lebar diameter buah per tanaman. Komponen bentuk buah per tanaman berkorelasi positif dengan bobot buah per tanaman, hal ini menunjukkan bahwa semakin besar skor bentuk buah per tanaman maka semakin berat bobot buah per tanaman. Menurut (Yulia, 2008) adanya korelasi antara karakter menyebabkan seleksi yang diterapkan akan mengikutsertakan secara simultan karakter-karakter lain yang berkorelasi dengan karakter utamanya.

Berdasarkan hasil penelitian Familia (2003), salah satu karakter tanaman yang dapat mempengaruhi hasil produksi yaitu karakter buah. Kisaran jumlah buah per tanaman berkorelasi positif dengan diameter buah dan bobot buah terung. Keragaman karakter buah pada tanaman penting dalam menentukan metode terbaik

Tabel 2. Koefisien korelasi antara bentuk buah dan hasil pada terung ungu.

\begin{tabular}{lc}
\hline Variabel Hasil & Bentuk buah \\
\hline Bobot buah & $0,52^{*}$ \\
Diameter buah & $0,72^{*}$ \\
Panjang buah & 0,02 \\
Bobot benih & $-0,15$
\end{tabular}

Keterangan: *)berkorelasi pada taraf 0,05 menggunakan analisis Korelasi Sperman. yang dibutuhkan untuk memperoleh hasil produksi. Karakter tersebut dapat digunakan sebagai kriteria seleksi atau sebagai petunjuk untuk menambah penampilan keturunan suatu tanaman.

Dari hasil pengujian viabilitas benih terung ungu bahwa perlakuan bentuk buah tidak berpengaruh terhadap viabilitas benih yang dihasilkan kecuali pada pengujian bobot kering kecambah normal dapat disajikan pada Tabel 3. Bobot kering kecambah normal paling tinggi berasal dari bentuk buah skor 3 yaitu bentuk buah bulat sedikit oval. Berdasarkan analisis korelasi pada Tabel 4 menunjukkan tidak adanya korelasi antara perlakuan bentuk buah terung ungu dan viabilitas benih. Menurut Shaban (2000) faktor yang mempengaruhi mutu benih yaitu faktor genetik antara lain kekerasan benih, warna benih, dan ukuran benih. Meskipun bentuk buahnya berbeda tetapi mungkin kekerasan benih, warna benih, dan ukuran benih tidak berbeda sehingga menghasilkan viabilitas benih terung ungu tidak beda. Namun bobot kering kecambah normal menunjukkan hasil yang berbeda. Bobot kering kecambah normal paling tinggi berasal dari bentuk buah skor 3 yaitu bentuk buah bulat sedikit oval.

Menurut penelitian Ismail (1990), bahwa ukuran buah terung yang berbeda tidak berpengaruh nyata terhadap viabilitas benih dengan tolok ukur daya berkecambah dan keserempakan tumbuh. Daya simpan benih dari buah panjang, sedang, dan pendek tidak berbeda nyata berdasarkan tolok ukur tersebut. Viabilitas benih merupakan daya hidup benih yang dapat ditunjukkan melalui gejala metabolisme dan gejala

Tabel 3. Rekapitulasi pengujian nilai tengah pengaruh bentuk buah pada viabilitas benih terung ungu yang telah disimpan 6 bulan.

\begin{tabular}{cccccc}
\hline \multirow{2}{*}{ Perlakuan } & \multicolumn{5}{c}{ Variabel Pengamatan } \\
\cline { 2 - 6 } & TKN (\%) & KCB (\%/ hari) & KSB (\%/ hari ke 11) & BKKN (g) & 100 Butir (g) \\
\hline Skor 1 & $69,50 \mathrm{a}$ & $9,66 \mathrm{a}$ & $64,50 \mathrm{a}$ & $1,14 \mathrm{~b}$ & $0,46 \mathrm{a}$ \\
Skor 3 & $54,25 \mathrm{a}$ & $7,22 \mathrm{a}$ & $47,50 \mathrm{a}$ & $1,18 \mathrm{a}$ & $0,42 \mathrm{a}$ \\
Skor 5 & $68,75 \mathrm{a}$ & $9,94 \mathrm{a}$ & $67,50 \mathrm{a}$ & $1,14 \mathrm{~b}$ & $0,48 \mathrm{a}$ \\
Skor 7 & $66,25 \mathrm{a}$ & $8,92 \mathrm{a}$ & $65,25 \mathrm{a}$ & $1,15 \mathrm{~b}$ & $0,47 \mathrm{a}$ \\
\hline Rata-Rata & 64,70 & 8,94 & 61,18 & 1,15 & 0,46 \\
\hline BNJ Hitung & 1,90 & 1,54 & 2,61 & 59,9 & 2,74 \\
\hline BNJ Tabel & \multicolumn{5}{c}{} \\
\hline
\end{tabular}

Keterangan : *) angka-angka yang diikuti dengan huruf yang sama pada lajur yang sama tidak berbeda pada taraf uji BNJ $\alpha 5 \%$. TKN = Daya berkecambah, KCB = Kecepatan berkecambah, KSB = Keserempakan berkecambah, BKKN = Bobot kering kecambah normal, Skor $1=$ Bentuk buah bulat, Skor $3=$ Bentuk buah bulat sedikit oval, Skor $5=$ Bentuk buah oval, Skor $7=$ Bentuk buah lonjong. 
Tabel 4. Koefisien korelasi antar bentuk buah dengan viabilitas benih terung yang telah disimpan 6 bulan

\begin{tabular}{ll}
\hline Viabilitas Benih Terung & Bentuk Buah \\
\hline Total kecambah normal & $-0,07$ \\
Kecepatan berkecambah & 0,00 \\
Keserempakan berkecambah & 0,16 \\
Bobot kering kecambah normal & 0,03 \\
Bobot 100 butir & 0,24 \\
\hline
\end{tabular}

Keterangan: menggunakan analisis Korelasi Sperman.

pertumbuhan, selain itu total kecambah normal juga merupakan tolok ukur parameter viabilitas benih (Matula, 2001). Pada umumnya viabilitas benih diartikan sebagai kemampuan benih untuk tumbuh menjadi kecambah. Perbedaan vigor dapat disebabkan oleh ukuran benih. Benih yang ukurannya tidak berbeda dalam varietas yang sama akan diperoleh vigor benih yang relatif sama jika faktor yang lain sama (Purwanti, 2004).

Penggunaan benih bermutu menjamin keberhasilan petani dalam meningkatkan produksi terung ungu. Bobot kering kecambah normal dapat digunakan sebagai acuan untuk pemulia, bahwa bobot kering kecambah normal yang tinggi dapat menggambarkan pemanfaatan cadangan makanan dalam benih yang efisien. Perbaikan daya hasil terung dapat dilakukan melalui seleksi tidak langsung terhadap bobot buah per tanaman.

Berdasarkan analisis korelasi yang telah dilakukan, maka karakter hasil yang dapat digunakan untuk melakukan seleksi tidak langsung terhadap bobot buah per tanaman adalah diameter buah karena memiliki nilai keeratan yang tinggi dan positif. Oleh karena itu, dengan adanya korelasi dapat dipakai sebagai seleksi tidak langsung untuk menciptakan varietas unggul baru bagi pemulia tanaman.

\section{KESIMPULAN}

Terdapat korelasi positif antara bobot buah per tanaman dengan diameter buah, panjang buah per tanaman, bobot benih per tanaman, dan bentuk buah. Bobot buah dan diameter buah memiliki nilai keeratan yang tinggi dan positif. Pengujian viabilitas benih terung ungu menunjukkan bahwa perlakuan bentuk buah tidak berpengaruh terhadap viabilitas benih yang dihasilkan kecuali pada pengujian bobot kering kecambah normal. Bobot kering kecambah normal paling tinggi berasal dari bentuk buah skor 3 yaitu bentuk buah bulat sedikit oval.

\section{DAFTAR PUSTAKA}

Astuti, P. 2004. Kajian suhu ruang simpan terhadap kualitas benih kedelai hitam dan kedelai kuning. Jurnal Ilmu Pertanian 11(1) : 22 -31

Badan Pusat Statistik, 2013. Statistik Indonesia. Jakarta.

Familia, N. S. 2003. Korelasi dan analisis koefisien lintas karakter agronomi terung (Solanum Melongena L.). Jurnal Ilmu Pertanian Indonesia 38 (1): 60-66

Ganefianti, D. W, Yulian, dan Suprapti, A. N. 2006. Korelasi dan sidik lintas antara pertumbuhan komponen hasil, dan hasil dengan gugur buah pada tanaman cabai. Jurnal Akta Agrosia 9(1): $1-6$.

IBPGR, 1990. Descriptors for Eggplant. International Board for Plant Resources. Italy. $128 \mathrm{hlm}$.

Ismail, W. 1990. Pengaruh ukuran, tingkat kemasakan, dan lama penundaan ekstraksi buah terhadap viabilitas benih terung (Solanum melongena L.). Jurnal Ilmu Pertanian Indonesia 15(3): 153-157

Matula, E. A. 2001. Pengujian viabilitas dan vigor benih beberapa jenis tanaman yang berbeda di pasar kota ambon. Jurnal Agrologia Volume 2 (1): $1-9$

Nugroho, S., Syahrul, A., dan Resi, V. 2008. Kajian hubungan koefisien korelasi pearson (r), spearman -rho $(\rho)$, kendall-tau $(\tau)$, gamma $(G)$, dan somers. Jurnal Gradien 4(2): 372381

Purwanti, S. 2004. Study of storage temperature on the quality of black and yellow soybean seed. Jurnal Ilmu Pertanian 11 (1):22-31.

Shaban, M. 2000. Study on some a spects of seed viability and vigor. International journal of Advanced Biological and Biomedical Reserch 12(1): $1-8$

Simanjuntak, F. A. 2003. Karakterisasi keragaman fenotipik tanaman terung (Solanum Melongena L.). Jurnal Ilmu Pertanian 10 (2): 17-25

Simatupang, A. 2010. Pengaruh beberapa jenis pupuk organiak terhadap pertumbuhan dan hasil tanaman terung (Solanum Melongena L.). Jurnal Agronomi 9(1):1-5

Sudarmo, H. 2007. Variasu genetik, heritabilitas, dan korelasi genotipe sifat-sifat penting tanaman wijen. Jurnal Litri 13(3): 1-9

Yulia, A. 2008. Korelasi genetik antara berkas pembuluh dengan beberapa karakter penting pada kedelai. Jurnal Agronomi 9(1):1-4 